\title{
Towards a Paradigm Shift in Polar Organometallic Chemistry
}

\author{
Eva Hevia*
}

\begin{abstract}
Core tools of synthetic chemistry, polar organometallic reagents (typified by organolithium and Grignard reagents) are used worldwide for constructing compounds, especially aromatic compounds, which are ubiquitous in organic chemistry and thus in numerous commodities essential to everyday life. By isolation and characterisation of key organometallic intermediates, research in our group has led to the design of polar mixed-metal reagents imbued with synergistic effects that display chemical properties and reactivity profiles far exceeding the limits of traditional single-metal reagents. These studies have improved existing, or established new fundamentally important, synthetic methodologies based on either stoichiometric or catalytic reactions. Bimetallic cooperative effects have been demonstrated in an impressive array of important bond forming reactions including deprotonative metallation, transition metal-free $\mathrm{C}-\mathrm{C}$ bond formation and metal-halogen exchange to name just a few. Towards greener, more sustainable, safer chemical transformations, our group has also pioneered the use of polar organometallic reagents under air and/or with water present using biorenewable solvents such as Deep Eutectic Solvents (DES) and 2-methyl THF. Herein we summarize some of our recent efforts in this intriguing area, which we believe can make inroads towards a step change in the practice and future scope of polar organometallic chemistry.
\end{abstract}

Keywords: Catalysis · Chemical cooperativity · Green chemistry · Organometallic · Sustainability

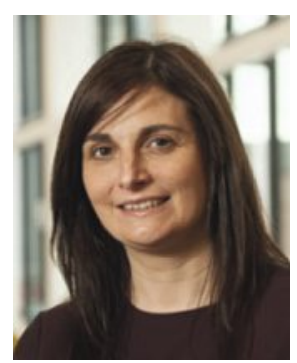

Eva Hevia received both her MSci degree in Chemistry and her PhD degree from the Universidad de Oviedo (Spain) in 1998 and 2002 respectively. After a three-year position at the University of Strathclyde (Glasgow, UK) working as a Marie Curie Fellow with Professor Robert Mulvey, in 2006 she took up a Royal Society University Research Fellowship and Lectureship there. Subsequently she was promoted to Full Professor in 2013. In February 2019, Eva moved to the University of Bern to take up a full professorship in Inorganic Chemistry. Research in her group focuses on polar organometallic chemistry at the crossroads of inorganic, organic, and green chemistry. Eva is an elected fellow of the European Academy of Sciences and her research has been recognized with several awards including the 2017 RSC Corday-Morgan Prize and the 2019 Organometallic Chemistry Award by the Spanish Royal Society of Chemistry

\section{Context and Scope}

Polar organometallic reagents, of which organolithium and Grignard reagents are the best known, have been seminal to the development of synthetic chemistry over the past 50 years. Staple reagents in academic synthetic laboratories worldwide, they are especially in high demand for functionalising aromatic and heterocyclic compounds and so are indispensable in the chemical industry (e.g. for the manufacture of agrochemicals, electronic materials, pharmaceuticals and other medicines). Their success lies in their high reactivity as a consequence of the large (for lithium) to medium (for magnesium) ionicity of their metal-carbon bonds, which makes them essential tools for carrying out numerous transformations in synthesis and catalysis. Taming this high reactivity can be challenging however, and side reactions such as hydrolysis/oxidation of reagents, decomposition of interme- diates, unwanted rearrangements, and functional group attacks are common. The use of polar organometallic reagents is therefore complicated by the need for restrictive protocols including for example, mandatory dry oxygen-free organic solvents, inert atmospheres and low temperatures. The high reactivity can also compromise selectivity leading to complex mixtures and poor product yields, which necessitate additional separation steps and generate lots of waste. Such problems can jeopardize large scale processes in industry due to the extra costs and time incurred in solving these problems. ${ }^{[1]}$ In addition, hazardous volatile organic compounds (VOCs) used as common solvents in polar organometallic chemistry still represent $80-90 \mathrm{wt}$.\% of the non-aqueous materials used in a typical chemical manufacturing process despite their toxicity, high flammability, non-biodegradability and tendency to accumulate in the atmosphere. ${ }^{[2]}$

To address some of these pressing challenges, an emerging and exciting area of polar organometallic chemistry focusses on the development of bimetallic formulations that $(i)$ do not necessarily require such restrictive protocols, and (ii) which can offer better performances than conventional monometallic organolithium and Grignard reagents. ${ }^{[3-6]}$ When an alkali metal is paired with a lower polarity main group metal such as zinc norms can be broken. For example, while zinc is a stronger Lewis acid than lithium in their separated monometallic compounds, when both are combined in the same molecule the lithium coordination sphere can often be more accessible to an external Lewis base than the zinc coordination sphere that will usually be saturated by three anionic ligands (Scheme 1). Such alkali metal-low polarity metal cooperativities can also offer enhanced performance, superior chemoselectivity and better functional group tolerance (as exemplified in Scheme 1 for the synthesis of $\left[\left\{(\mathrm{TMEDA})_{2} \mathrm{Li}\right\}^{+}\left\{\mathrm{ZnEt}_{3}\right\}^{-}\right](\mathbf{1})$, which can selectively transfer one ethyl group to nitrolefins at room temperature, whereas EtLi or $\mathrm{ZnEt}_{2}$ on their own fail to promote the alkylation of these sensitive organic substrates). ${ }^{[7]}$ Such aptitudes 
make these bimetallic systems attractive in key organic transformations such as metal-halogen exchange and deprotonative metallation as well as $\mathrm{C}-\mathrm{C}$ bond forming processes. ${ }^{[3-7]}$

It should be noted that s-block bimetallic compounds constitute one of the oldest types of known organometallic compounds, having been pioneered by Wanklyn with the synthesis of $\mathrm{NaZnEt}_{3}$ in $1858 .{ }^{[8]}$ For many years they lay in obscurity as mere curiosities but over the past two decades they have emerged as highly versatile reagents in organic synthesis. Some key landmarks in this area include Uchiyama's $\mathrm{Li}_{2} \mathrm{Zn}^{t} \mathrm{Bu}_{4}$, which effectively promotes direct $\mathrm{Zn}$-halogen exchange reactions of an assortment of aromatic substrates, ${ }^{[9]}$ as well as the development of strong, regioselective deprotonating reagents powered by TMP $(2,2,6,6$-tetramethylpiperidide) ligands such as Knochel's turbo Grignard reagents ${ }^{i} \mathrm{PrMgCl} . \mathrm{LiCl}$ and TMPMgCl.LiCl. ${ }^{[10]}$ More often than not, these bimetallic reagents are prepared in situ, and limited attention has been given to their isolation or characterization. Shedding some light in the intriguing constitution of these species, Mulvey's work on the synthesis of mixed alkyl/amide alkali-metal magnesiates and zincates has enabled remote di-magnesiation/dizincation of aromatic molecules which have coined the concept of alkali-metal-mediation-metallation. [11]

Inspired by these excellent contributions, herein we showcase some of our most recent studies on developing tailor-made bimetallic reagents for applications in organic synthesis containing earth-abundant metals. This research is presented from a metal-focused perspective, with a special interest on the isolation and characterization of the organometallic intermediates prior to electrophilic interception, which can help us to advance the understanding of bimetallic cooperation and how to maximize synergistic behaviours. ${ }^{[12]}$ Along with our studies in cooperative bimetallics, towards the development of more sustainable polar organometallic chemistry, here we also include an account of our work on the use of organolithium reagents in non-conventional biorenewable solvents, which enable the use of these reagents in the presence of air and moisture while operating at room temperature, a trio of conditions typically forbidden in polar organometallic chemistry. ${ }^{[13]}$

\section{Mixed-Metal Reagents for Deprotonative Metallation: Synchronised versus Stepwise Cooperation}

Deprotonative metallation is one of the most useful synthetic tools to functionalize aromatic/heterocyclic molecules enabling their incorporation into more complex molecular frameworks. Basic and sterically hindered Group 1 amides, in particular
LiTMP or LDA $($ TMP $=2,2,6,6$,-tetramethylpiperidide, DA = diisopropylamide) are commonly used, and while they are efficient in many cases for routine $\mathrm{C}-\mathrm{H}$ to $\mathrm{C}-$ metal transformations, in some occasions when used for the deprotonation of sensitive organic substrates (such as for example $N$-heterocyclic molecules or fluoroarenes), reactions can be problematic due to their lack of selectivity and/or the poor stability of the organolithium intermediates generated, which can undergo unwanted side reactions even when working under strict cryogenic conditions. Exploiting cooperative effects between metals, we have developed new strategies for maximizing efficiencies in $\mathrm{C}-\mathrm{H}$ metallation reactions combining a group 1 metal with low polarity $\mathrm{Zn}, \mathrm{Al}$ or $\mathrm{Mg}$. ${ }^{[14-16]}$ By carefully choosing the ligands, employing basic and sterically demanding groups such as TMP or $\mathrm{CH}_{2} \mathrm{SiMe}_{3}$ we can not only kinetically activate the base, but also promote trapping and stabilizing of otherwise highly unstable organic anions. [17-21]

Combining mechanistic studies with identifying key organometallic intermediates from solution mixtures, we have established that cooperative reactions between mixed-metal reagents and aromatic substrates can follow two distinct pathways. In concerted cooperative reactions, the metal centres housed within the same bimetallic structure operate in a synchronised manner, enabling low polarity metallations, with unique regioselectivities, not available using conventional single metals, as exemplified in Scheme 2a for the 2,5-dizincation of pyrazine (pyz) by lithium zincate [(THF)LiZn(TMP) $\left.t \mathrm{Bu}_{2}\right]$ (2) affording [2,5-\{(THF) $)_{2} \mathrm{LiZn}(\mathrm{TMP})$ $\left.t \mathrm{Bu})\}_{2}\left(\mathrm{C}_{4} \mathrm{H}_{2} \mathrm{~N}_{2}\right)\right](3)$. ${ }^{[17]}$ Illustrating the synergistic behaviour between the metals, previous pyz metallation studies has shown that when using LiTMP in THF at $-78{ }^{\circ} \mathrm{C}$, a four molar excess of the base is required to furnish 2-substituted derivatives in modest yields (39-65\%, depending on the electrophile) mixed in some cases with 2,5-disubstituted species (16\%). ${ }^{[22]}$ On the other hand, $\mathrm{Zn} t \mathrm{Bu}_{2}$ fails to deprotonate this heterocycle, forming instead coordination adduct $\left[\left\{\mathrm{Zn} t \mathrm{Bu}_{2}\right\}_{3}\{\text { pyz }\}_{4}\right]{ }^{[17]}$ Considering the inherent instability of $\alpha$-metallated diazines, it may seem surprising that a sensitive pyrazinyl di-carbanion can be trapped in crystalline form at room temperature and structurally defined, but this is where the structure of $\mathbf{3}$ becomes very informative as its shows that the heterocyclic $\left\{\mathrm{C}_{4} \mathrm{H}_{2} \mathrm{~N}_{2}\right\}^{2-}$ unit is stabilized through coordination by both the $\mathrm{Li}$ and $\mathrm{Zn}$ centres that tie up the lone pairs of the $\mathrm{N}$ and $\mathrm{C}$ atoms, respectively (Scheme $2 \mathrm{a}$ )

Bimetallic cooperation can also operate in a stepwise manner with one metal (e.g. Li) performing metallation, while another (e.g. $\mathrm{Al}$ or $\mathrm{Ga}$ ) drives the equilibrium towards products, to transform low yielding reactions to high yielding through the trapping of the emergent anion as shown in Scheme $2 b$ for the
Scheme 1. Accessing cooperative bimetallic reagents via cocomplexation approaches illustrated by the synthesis of $\left[\left\{(\text { TMEDA })_{2} \mathrm{Li}^{+}\right\}^{+}\left(\mathrm{ZnEt}_{3}\right\}^{-}\right]$and its applications in transition metalfree alkylation of nitrolefins. ${ }^{[7]}$

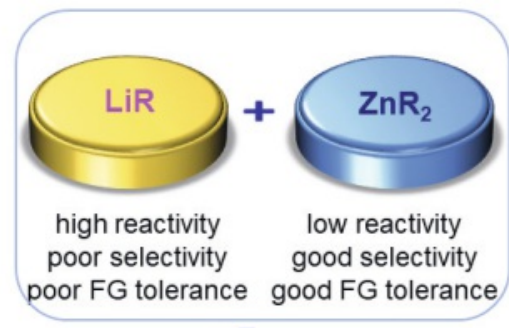

co-complexation

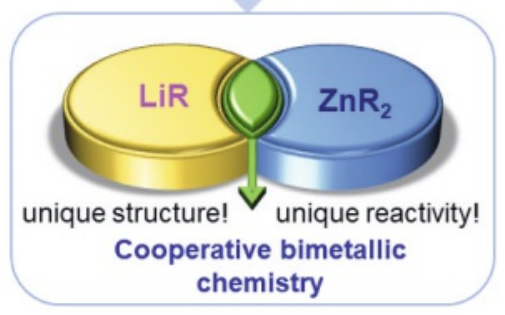

(i) Synthesis and structure of mixed lithium/zinc reagent

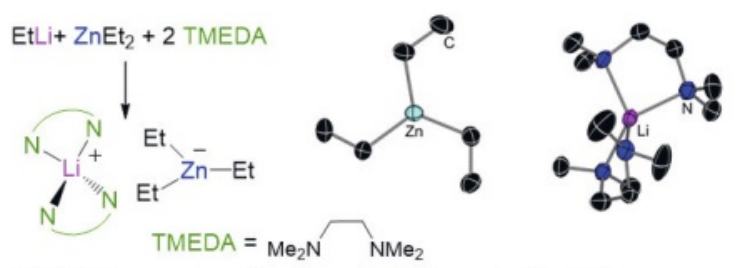

(ii) Li/Zn cooperation for alkylation of nitrolefins

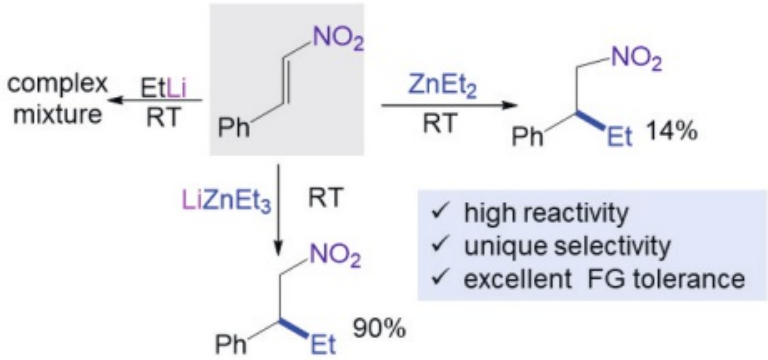


(a) Concerted cooperation via mixed-metal reagent
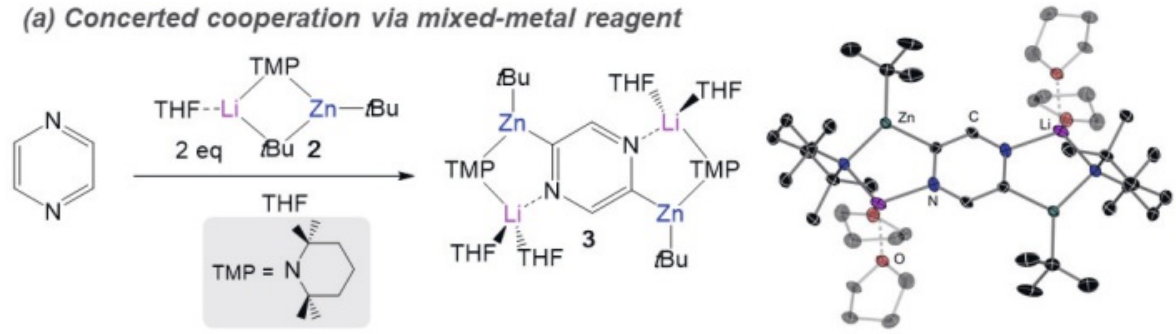

(b) Stepwise cooperation (TMT) via single-metal reagents
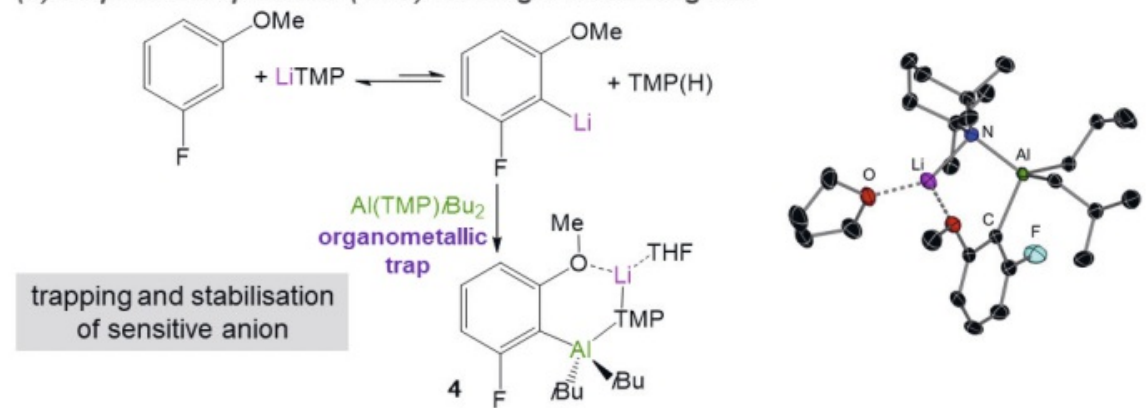

Scheme 2. Cooperative metalation: (a) direct 2, 5-dizincation of pyrazine by mixed-metal base [(THF)Li(TMP)ZntBu $\left.{ }_{2}\right]$ (2); ${ }^{[17]}$ and (b) stepwise alumination of 3-fluoroanisole by trans-metal-trapping approach using Li(TMP) and $\mathrm{Al}(\mathrm{TMP}) i \mathrm{Bu}$ in sequence. ${ }^{[21]}$ deprotonation of 3-fluoroanisole using a combination of the utility amide LiTMP and the organometallic trap [Al(TMP) $\left.i \mathrm{Bu}_{2}\right]_{.}{ }^{[21]}$ This type of stepwise metallation has been labelled trans-metal trapping (TMT) as the products of these reactions are the result of a partial transmetallation process, with the reaction stopping at the crossover co-complex, $\left[(\mathrm{THF}) \mathrm{LiAl}(\mathrm{Ar})(\mathrm{TMP}) i \mathrm{Bu}_{3}\right](\mathbf{4})(\mathrm{Ar}=$ $3-\mathrm{F}-\mathrm{C}_{6} \mathrm{H}_{3}(\mathrm{OMe})$, Scheme $\left.2 \mathrm{~b}\right) .{ }^{[19-21]}$ TMT is driven by the steric incompatibility of the single metal reagents that fail to engage in a mixed-metal complex. In this approach the choice of organometallic trap should fulfil two key requirements: firstly, the metal should form strong enough $\mathrm{M}-\mathrm{C}$ bonds to stabilize the generated anions, in the case of $\mathbf{4}$ the sensitive fluoroaryl; but secondly, in order to facilitate further functionalization of the aromatic fragment, the resulting $\mathrm{M}-\mathrm{C}$ bond should also be labile enough to promote onward reactivity with electrophiles. ${ }^{[23]}$

Reaching wider applications, mixed-metal combinations operating in a concerted-cooperative or stepwise-cooperative manner have also been exploited successfully for functionalising $\mathrm{N}$-heterocyclic carbenes (NHCs), ${ }^{[24-29]}$ establishing new ways to trap dianionic NHC fragments in reactions of unprecedented chemoselectivity ${ }^{[28]}$ as well as enabling lateral metallation of saturated NHCs via stepwise (or trans-metal-trapping) approaches. ${ }^{[29]}$

A second generation of cooperative bimetallics for deprotonative metallation has also been developed by replacing the low polarity s-block metal by divalent earth-abundant transition metals such as $\mathrm{Mn}$ (II) and Fe(II). ${ }^{[30-32]}$ Thus, direct ferration of a wide range of fluoroarenes has been established by using tris(amido) sodium ferrate [(dioxane) $\left.\mathrm{NaFe}(\mathrm{HMDS})_{3}\right]$ (5) $\left(\mathrm{HMDS}=\mathrm{N}\left(\mathrm{SiMe}_{3}\right)_{2}\right),{ }^{[32]}$ as shown in Scheme 3 for the metallation of 1,3,5-trifluorobenzene. ${ }^{32]}$ Interestingly while deprotonation of fluoroarenes using conventional lithium bases can be extremely challenging due to the exceptional fragility of generated intermediates, which can decompose even at $-78{ }^{\circ} \mathrm{C}$, these sodium-mediated ferrations occur regioselectively at room temperature with an excellent stoichiometric control enabling unprecedented di-ferration of some of these fluoroarenes as shown for 1,2,4,5-tetrafluorobenzene in $\mathbf{7}$ (Scheme 3 ). This reactivity is most surprising considering the noticeable lower polarity of $\mathrm{Fe}$ vs $\mathrm{Na}(\chi \mathrm{Fe}=1.83 ; \chi \mathrm{Na}=0.93)$, which limits the applications of iron amides in deprotonative metallalation. Isolation of key intermediates 6 and $\mathbf{7}$ has provided unique insights on how $\mathrm{Na}$ and Fe can cooperatively induce these metallation reactions that neither sodium or iron amides are capable of facilitating on their own. ${ }^{[32]}$ Preliminary mechanistic studies suggest that initially the fluoroarene could coordinate to $\mathrm{Na}$ in $\mathbf{5}$ via a dative $\mathrm{Na}-\mathrm{F}$ bond, bringing its adjacent $\mathrm{H}$ into close proximity to the anionically activated ferrate $\left\{\mathrm{Fe}(\mathrm{HMDS})_{3}\right\}^{-}$moiety, priming the intramolecular $\mathrm{Fe}-\mathrm{H}$ exchange. As shown for 7 in Scheme 3, the proposed dative Na...F interactions are retained in the organometallic intermediate whereas each $\mathrm{Fe}$ centre forms a strong $\sigma$-bond with the $\mathrm{C}$ atom that has experienced the metallation, ortho to the $\mathrm{F}$ atom that coordinates to $\mathrm{Na}$.

\section{Cooperative Bimetallics for Metal-Halogen Exchange and C-C Bond Forming Processes}

Our work probing salt influences on earth-metal-rich organometallic reagents establishes that forming kinetically activated bimetallic reagents combining magnesium and zinc can selectively functionalise organic substrates via unprecedented direct $\mathrm{Zn}$-halogen exchange reactions. ${ }^{[33]}$ Switching on cooperative effects, these bimetallic 'magnesium/zinc hybrids' show unique reactivity profiles unrepeatable by either magnesium or zinc reagents on their own (Scheme 4). Thus trans-metallation of 3 equivalents of $t \mathrm{BuMgCl}$ with $\mathrm{ZnCl}_{2}$ furnishes mixed $\mathrm{Mg} / \mathrm{Zn}$ complex $\left.\left\{\mathrm{Mg}_{2} \mathrm{Cl}_{3}(\mathrm{THF})_{6}\right\}^{+}\left\{\mathrm{Zn} t \mathrm{Bu}_{3}\right\}^{-}\right] \mathbf{( S )}^{2}$ ) which can effectively promote direct $\mathrm{Zn}-\mathrm{I}$ exchange reactions with several aromatic halides ArI in short periods of time at room temperature in THF solution. NMR reaction monitoring and structural studies probing the organometallic intermediates in these transformations show that the $\mathrm{Zn}-\mathrm{I}$ exchange takes place with an excellent atom economy, with the three alkyl groups present in $\mathbf{8}$ being active towards ArI to give magnesium tris(aryl) zincate $\left.\left\{\mathrm{Mg}_{2} \mathrm{Cl}_{3}(\mathrm{THF})_{6}\right\}^{+}\left\{\mathrm{ZnAr}_{3}\right\}^{-}\right]$(9) as illustrated in Scheme 4 for 4-iodotoluene. ${ }^{33 a]}$ Demonstrating the power of the $\mathrm{Mg} / \mathrm{Zn}$ cooperative partnership in $\mathbf{8}$, neither $t \mathrm{BuMg}$ $\mathrm{Cl}$ or $\mathrm{Zn} t \mathrm{Bu}_{2}$ can promote metal-iodine exchange reactions under the conditions of the study. Furthermore, the high atom economy of this transformation contrasts with previous studies using related lithium zincates $\left[\mathrm{LiZn} t \mathrm{Bu}_{3}\right]$ and $\left[\mathrm{Li}_{2} \mathrm{Zn} t \mathrm{Bu}_{4}\right]$ where equimolar amounts of the aromatic halide ArX and the mixed-metal reagents are required. ${ }^{[34]}$ Expanding the synthetic utility of these heterobimetallic systems, a wide range of homoleptic tris(aryl) zincate intermediates 9 have been prepared in situ and used as precursors in Pd catalysed cross-coupling reactions with substituted aryl halides, affording several asymmetrical bis(aryls) in excellent yields under mild reaction conditions without the need of any additive or polar cosolvent (Scheme 4).

More recently, in collaboration with Paul Knochel at LudwigMaximilians-Universität, Munich, we have found that commer- 
Scheme 3. Sodium-mediated ferration of fluoroarenes 1,3,5-trifluorobenzene and 1,2,4,5-tetrafluorobenzene by mixed-metal base [(dioxane) $\left.\mathrm{NaFe}(\mathrm{HDMS})_{3}\right](\mathbf{5}) \cdot{ }^{[32]}$

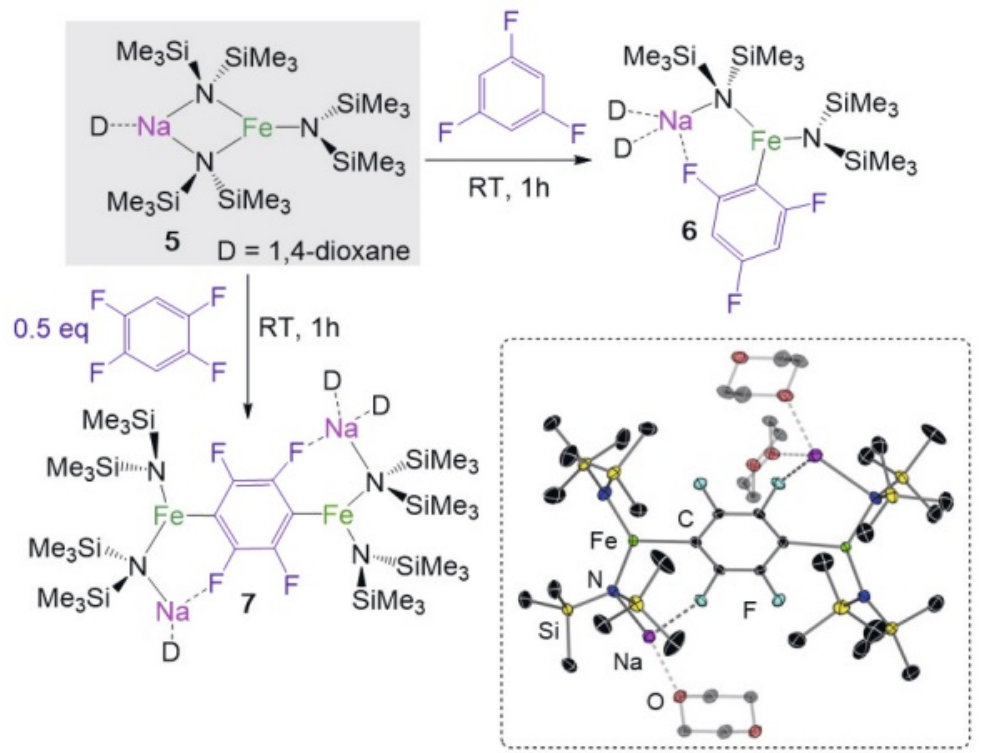

Scheme 4. Zn-I exchange and Pdcatalysed cross-coupling applications of aromatic substrates using $\mathrm{Mg} / \mathrm{Zn}$ hybrid reagents. ${ }^{[33]}$

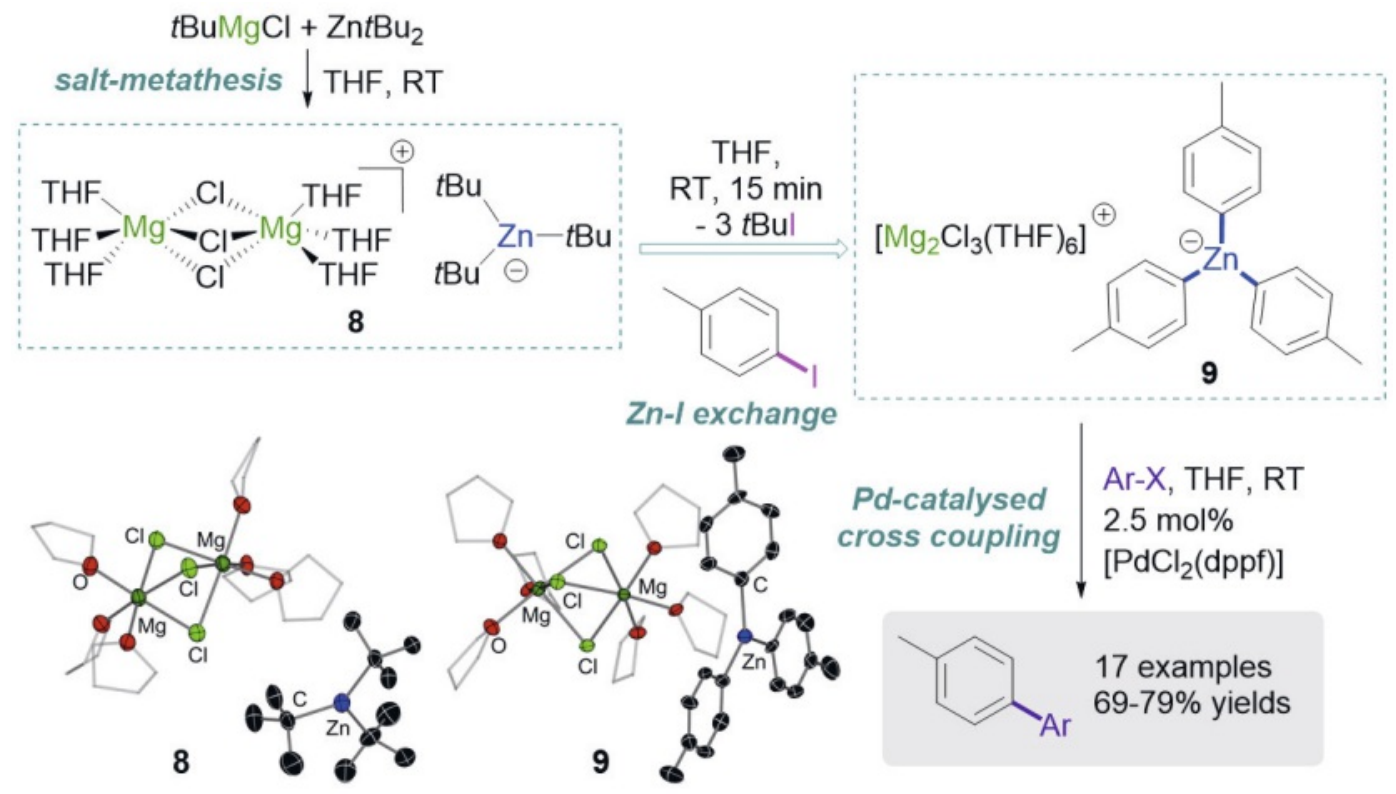

cially available $\mathrm{ZnEt}_{2}$ can be activated towards $\mathrm{Zn}-\mathrm{I}$ exchange with ArI on the addition of two equivalents of LiOR' (OR' = $\left.\mathrm{OCH}_{2} \mathrm{CH}_{2} \mathrm{~N}(\mathrm{Me}) \mathrm{CH}_{2} \mathrm{CH}_{2} \mathrm{NMe}_{2}\right)$. ${ }^{[35]}$ Structural and spectroscopic studies into the constitution and reactivity of these bimetallic mixtures support the formation of highly reactive lithium bis(alkyl) bis(alkoxy)zincates of type $\left[\mathrm{Li}_{2} \mathrm{Zn}\left(\mathrm{OR}^{\prime}\right) \mathrm{Et}_{2}\right]$ where zinc is formally part of an electron-rich dianionic moiety. Interestingly, replacing $\mathrm{ZnEt}_{2}$ for $\mathrm{ZnsBu}_{2}$ enables direct $\mathrm{Zn}-\mathrm{Br}$ exchange at room temperature, with excellent functional group tolerance through the activation of both $s \mathrm{Bu}$ groups on $\mathrm{Zn}$ (Scheme 5a). Quenching of the in situ generated zinc organometallics with various electrophiles produced a range of functionalized (hetero)arenes, demonstrating the extensive synthetic scope of this approach. ${ }^{[35]}$

Profiting from 'built-in' alkali-metal Lewis acidic sites adjacent to anionically activated sites, tetraorganozincates $\mathrm{Li}_{2} \mathrm{ZnR}_{4}(\mathrm{R}$ = aryl or alkyl) have also found applications in $\mathrm{C}-\mathrm{H}$ arylation/ alkylation of $N$-electron deficient heteroaromatics such as acridine or pyrazine (Scheme 5b). ${ }^{[36]}$ This bimetallic approach is compatible with milder reaction conditions (MW, low reaction times) than existing transition-metal $(\mathrm{Ni}, \mathrm{Rh})$ catalysis, which requires use of diarylzincs and harsh reaction conditions $\left(60-130{ }^{\circ} \mathrm{C}\right.$, $20 \mathrm{~h}$ ). More recently we have found that tetraorganozincates enable the transition metal- and ligand-free nucleophilic addition to nitroolefins for the synthesis of valuable nitroalkanes in up to $98 \%$ yield under mild conditions $\left(0{ }^{\circ} \mathrm{C}\right)$. Illustrating the versatility and enhanced nucleophilic power of these bimetallic systems, this method offers a broad substrate scope, facilitating also direct arylation reactions and with high chemoselectivity when working in the absence of additional solvents. ${ }^{[7]}$ This method contrasts with previous examples from the literature where arylation of $\beta$-nitrostyrenes has only being realised using $\mathrm{Rh}$ or Pd catalysis with boronic acids or arylsiloxanes, ${ }^{[37]}$ and also with the fact that $\mathrm{ZnAr}_{2}$ on their own are completely inert towards these type of organic substrates.

In addition, in a collaboration with Janssen Pharmaceutica, we have developed a highly efficient method, which enables the diastereoselective arylation of bromosugars without the need for transition-metal catalysis while operating at room temperature (Scheme 5c). ${ }^{[38]}$ This new approach relies on the stepwise cooperation of homobimetallic arylzinc mixtures, where the close interplay between two distinct zinc reagents, $\mathrm{ZnAr}_{2}$ with the strong Lewis acid $\left[\left(\mathrm{ZnAr}^{\mathrm{F}}\right)\right]\left(\mathrm{Ar}^{\mathrm{F}}=\mathrm{C}_{6} \mathrm{~F}_{5}\right)(\mathbf{1 0})$, enables direct $\mathrm{C}(\mathrm{sp} 2)-\mathrm{C}(\mathrm{sp} 3)$ bond formation. Remarkably while it operates at room temperature, this $\mathrm{Zn} / \mathrm{Zn}$ bimetallic approach offers greater levels of stereoselectivity and superior yields than those reported in the literature using transition-metal catalysis. Kinetic investigations have uncovered a multi-step mechanism initiated by bro- 
(a)

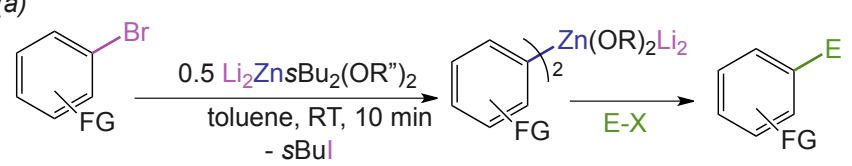$$
\mathrm{R}^{\prime}=\mathrm{N}_{\text {l }}^{\mathrm{N}^{\prime}}
$$

up to $98 \%$ yields excellent FG tolerance

(b)<smiles>c1ccc2nc3ccccc3cc2c1</smiles>

(i) $\mathrm{Li}_{2} \mathrm{ZnPh}_{4}$ $\underset{\mathrm{THF}, \mathrm{MW},}{\stackrel{25^{\circ} \mathrm{C}, 20 \mathrm{~min}}{\longrightarrow}}$ (ii) $\mathrm{DDQ}$

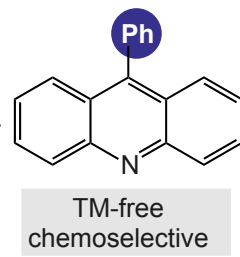

(c)

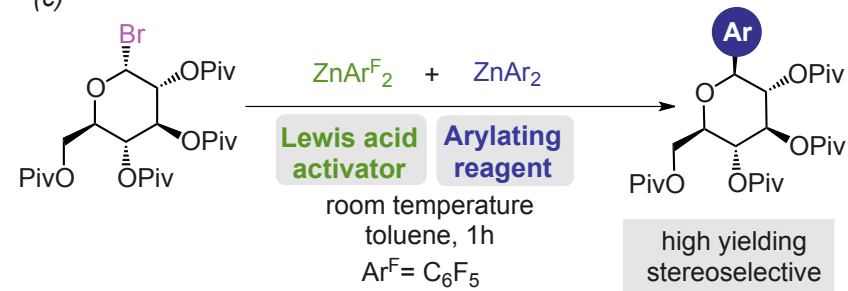

Scheme 5. Selected examples of s-block bimetallic cooperation in zinc chemistry for selective $\mathrm{C}-\mathrm{Br}$ functionalisation and transition metal-free C-C bond forming processes. ${ }^{[35,36,38]}$

mine abstraction facilitated by Lewis acidic 10, which in turn can transfer the bromide anion to the arylating zinc reagent to form a more nucleophilic zincate $\left\{\mathrm{ZnAr}_{2} \mathrm{Br}\right\}^{-}$, which then undergoes an electrophilic aromatic substitution with the oxocarbenium electrophile, to form the new $\mathrm{C}-\mathrm{C}$ bond.

\section{Developing s-Block Cooperative Bimetallic Catalysis}

Alkaline-earth metal catalysis is a rapidly evolving field, which has alerted the community to the vast reservoir of potential offered by group 2 metal complexes in homogeneous catalysis, as low-toxicity, cheap alternatives to transition metal systems. ${ }^{[39]}$ Thus, progress has been made in catalytic hydroamination, hydrosilylation, hydrogenation, and hydrophosphination for functionalising unsaturated organic molecules. ${ }^{[39]}$ Many applications have focused on hydroamination, where heavier group 2 elements $(\mathrm{Ca}$, $\mathrm{Sr})$ have shown remarkable catalytic abilities. Conversely, $\mathrm{Mg}$ has disappointed due to its smaller radius seemingly raising transition state barriers in the rate-determining alkene insertion step, showing similar behaviors to those previously reported in organo-lanthanide(III) catalysts. ${ }^{[40]}$ Overturning this trend, we have shown that $\mathrm{Mg}$ activated within a sodium magnesiate platform, can outperform $\mathrm{Ca}$ and $\mathrm{Ba}$ systems in hydroaminating isocyanates and carbodiimides, giving higher yields and superior substrate scope under milder conditions (Scheme 6). ${ }^{[41]}$ These seed results have uncovered the untapped potential of s-block cooperative catalysis, where the benefits that bimetallic reagents have displayed in stoichiometric transformations (e.g. enhanced reactivity, greater functional group tolerance, special regioselectivities) can be exported to catalytic regimes. By trapping key bimetallic intermediates, new mechanistic and structural insights on this ate-catalysed hydroamination processes have been gained, shedding new light on cooperative effects between $\mathrm{Na}$ and $\mathrm{Mg}$ and the important part that each metal plays in these reactions. Unique cooperativity arises because $\mathrm{Na}$ can act as a Lewis acid allowing the activation of the unsaturated organic substrate (isocyanate or carbodiimide) facilitating the intramolecular nucleophilic attack by the highly nucleophilic Lewis basic tris(magnesiate) anion (Scheme 6).

Highlighting the key role of the alkali metal in these catalytic processes, work studying more challenging processes such as alkyne/alkene hydroamination ${ }^{[42]}$ and intramolecular cyclisation of alkynols has uncovered a powerful synergistic effect between potassium and magnesium. ${ }^{[43]}$ Reflecting the relevance on the nucleophilicity of these alkali-metal magnesiates, higher order tetra(organo) magnesiates $\left[\mathrm{M}_{2} \mathrm{Mg}\left(\mathrm{CH}_{2} \mathrm{SiMe}_{3}\right)_{4}\right](\mathrm{M}=\mathrm{Na}, \mathrm{K})$, which are formally dianionic species, have proved to be much more efficient pre-catalysts for these processes than the related lower-order analogues $\left[\mathrm{MMg}\left(\mathrm{CH}_{2} \mathrm{SiMe}_{3}\right)_{3}\right]$. Thus, for example while $\left[\mathrm{K}_{2} \mathrm{Mg}\left(\mathrm{CH}_{2} \mathrm{SiMe}_{3}\right)_{4}\right]$ is able to promote the hydroamination of styrene or diphenylacetylene in quantitative yields at room temperature, $\left[\mathrm{KMg}\left(\mathrm{CH}_{2} \mathrm{SiMe}_{3}\right)_{3}\right]$ requires significant harsher reaction conditions $\left(80^{\circ} \mathrm{C}\right.$, longer reaction timescales). ${ }^{[42]}$ It should also be noted that the use of Lewis donors as additives can finely tune the coordination sphere of the alkali metal in these transformations, improving the efficiency of the catalysts, as recently observed for the intramolecular hydroalkoxylation of alkynols, where adding a stoichiometric quantity of 18-crown-6 as co-catalysts according to the alkali metal [i.e. $10 \mathrm{~mol} \% 18-\mathrm{c}-6$ for $5 \mathrm{~mol} \% \mathrm{~K}_{2} \mathrm{Mg}$ $\left.\left(\mathrm{CH}_{2} \mathrm{SiMe}_{3}\right)_{4}\right]$ reduces the reaction time from $22 \mathrm{~h}$ to just $3 \mathrm{~h}$, with an improvement in selectivity. ${ }^{[43]}$

\section{Towards Air- and Moisture-compatible Polar Organometallic Chemistry}

Organolithium reagents have been and remain pivotal for the development of synthetic chemistry. Exploiting the large polarity of their $\mathrm{Li}-\mathrm{C}$ bonds, these reagents are used worldwide in industry and academia for the functionalization of organic molecules. However, despite their enormous synthetic relevance, their use is handicapped by their requirements of low temperature, in order to control their reactivity, as well as the need for dry organic solvents and protective inert atmosphere protocols to avoid their
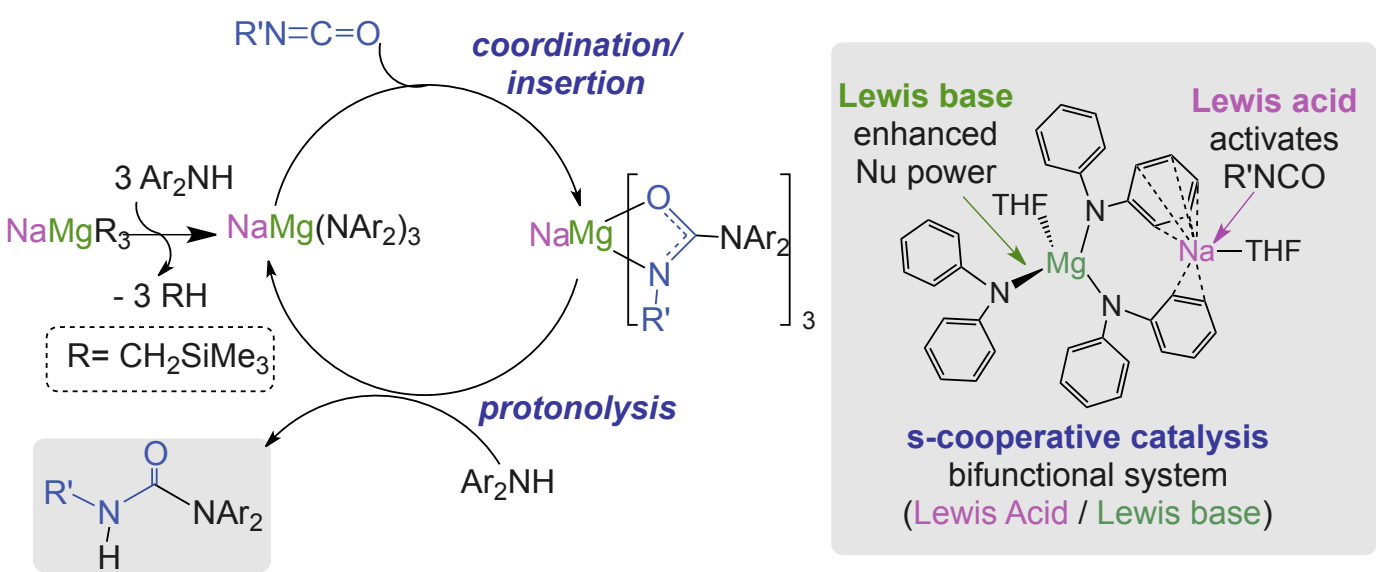

Scheme 6. Sodium magnesiatecatalysed hydroamination of isocyanates. ${ }^{[41]}$ 
fast decomposition. Thus, running organolithium chemistry under aerobic and/or hydrous conditions, without the need of dry toxic organic solvents is seen as an insurmountable challenge for synthetic chemists. ${ }^{[1]}$

Breaking down the formidable barrier between organometallic and aerobic/aqueous chemistry, in collaboration with Joaquin Garcia-Alvarez at the University of Oviedo, we have recently uncovered the potential of Deep Eutectic Solvents (DESs) as unprecedented green reaction media for chemoselective alkylation of ketones, imines and quinolines by RLi reagents at room temperature under air in the presence of water, a trio of conditions traditionally disallowed in this type of chemistry. ${ }^{[4-46,49]}$ Furthermore, in most cases conversions and chemoselectivities observed are superior than those observed in common toxic organic solvents, while working under inter atmosphere conditions with strict temperature control (Scheme 7).

Most DESs are combinations of two or three safe, inexpensive, and nature-inspired components able to engage in reciprocal hydrogen bond interactions to form a eutectic mixture with a melting point much lower than that of either individual component.[21] Compared to conventional organic solvents, DESs show high thermal stability, non-flammability and practically no vapour pressure, therefore low volatility. ${ }^{[47]}$ Typical DESs components (e.g. choline chloride, urea, natural carboxylic acids, amino acids and carbohydrates, polyalcohols, etc.) come from renewable sources (Scheme 7). Thus, their biodegradability is extraordinarily high, and their toxicity is non-existent or very low. ${ }^{[48]}$ Furthermore, the atom economy on the DESs formation is the highest possible as all initial components are included in the final mixture. All these factors have made DESs the chosen solvents in many areas, such as materials science, metal electrodeposition, nanotechnology, bio- and organocatalysis, to name just a few, ${ }^{[48]}$ whereas their applications in metal-mediated synthetic transformations using polar organometallics have remained virtually unexplored as the canon of this chemistry is incompatibility with protic solvents. ${ }^{[13]}$

Making a seemingly impossible step change possible, our work using DESs (based on the non-toxic and biorenewable ammonium salt choline chloride, $\mathrm{ChCl}$ ) edges closer towards developing air- and water-compatible polar organometallic chemistry. Initially we investigated the arylation/alkylation of ketones by RLi and $\mathrm{RMgX}$ reagents using DES combinations of $\mathrm{ChCl}$ with either water or glycerol (Scheme 7 (i)). ${ }^{[44]}$ Comparing reactivity profiles of these reagents in DESs with those in neat water revealed a kinetic ${ }^{[41]}$ activation in the former, favouring addition reactions over competing hydrolysis processes. Since then we have also extend- ed this approach to the addition of RLi reagents to both non-activated imines and quinolines in DESs under air, revealing a new sustainable methodology to access synthetically valuable amines (Scheme 7 (ii)). ${ }^{[45]}$ For these transformations the DES appears to have a dual role. First, it forms kinetically activated mixed-ammonium ate salts by co-complexation of the polar reagents (RLi or $\mathrm{RMgX})$ via the ammonium salt choline chloride $(\mathrm{ChCl}, \mathrm{H}$-bond acceptor component of the DES studied, Scheme 7). Second, it activates the organic substrate by forming $\mathrm{H}$-bonding interactions with the H-donor component of the DES (water or glycerol). ${ }^{46]}$ Broadening the applications of these DESs/RLi partnerships, we have also reported their uses in anionic olefin polymerization processes, establishing a new air- and moisture-compatible method to access a range of synthetically relevant polyolefins (Scheme 7 (iv)). ${ }^{[49]}$ Remarkably, these studies have revealed that the in situ formed polystyryl lithium intermediates exhibit a great resistance to hydrolysis in the eutectic mixture $1 \mathrm{ChCl/2Glycerol}$ (up to 1.5 h) hinting at an unexpected high stability that can be successfully exploited to create well defined di-block copolymers.

More recent studies assessing the use of lithium amides under aerobic conditions has revealed that sustainable biorenewable solvents such as glycerol or 2-methyl-THF enable effective amidation of esters and transamidation of amides furnishing a range of carboxamides. ${ }^{[50]}$ In the case of 2-methyl THF, the combination of structural and spectroscopic studies has allowed the isolation and characterisation of key organometallic intermediates, revealing the key role of this ethereal solvent in favouring the formation of small kinetically activated aggregates that, in turn, can react rapidly with the organic substrate before decomposition reactions by air or moisture can compete. ${ }^{[50]}$

\section{Conclusions and Outlook}

Polar organometallic reagents such as RLi or $\mathrm{RMgX}$ have a long history of applications in organic and organometallic chemistry, being utilised on a daily basis in synthetic laboratories across the world. However, their utility comes at a vast cost. They cannot come in contact with air or water and must be used in stringently dry toxic organic solvents, so they are expensive, unsustainable and have health concerns. Furthermore, their hard reactivity requires the use of severely restrictive protocols (low temperatures, inert atmospheres, dry-oxygen-free solvents) otherwise side reactions dominate. Overcoming these limitations requires a step change to make polar organometallic chemistry fit for purpose for the next 50 years. Our strategy to facilitate this step change is based on the development of novel earth-abundant mixed-metal
Scheme 7. Examples of air- and moisture compatible organolithium chemistry in Deep Eutectic Solvents (DESs). ${ }^{[4-46,49]}$
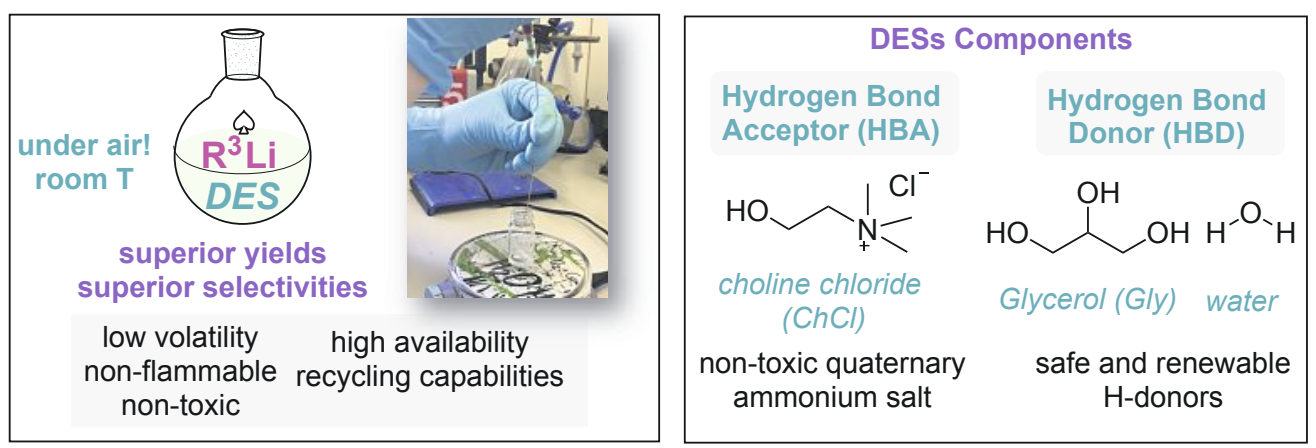

(i)

$\mathrm{R}^{1}{ }_{\mathrm{R}^{2}}+2 \mathrm{RLi} \frac{1 \mathrm{ChCl} / 2 \mathrm{H}_{2} \mathrm{O}}{\mathrm{rt} \text {, under air, } 3 \mathrm{sec}} \mathrm{R}_{\mathrm{R}^{1}}^{\stackrel{\mathrm{OH}}{\mathrm{H}_{\mathrm{R}}}} \underset{\mathrm{R}^{2}}{\mathrm{H}}$ (iii)

$\mathrm{Ar} \longrightarrow \mathrm{N}+2 \operatorname{ArLi} \frac{\text { Gly }}{\mathrm{rt} \text {, under air, } 3 \mathrm{sec}} \mathrm{Ar}$,

(iv) (ii) $\mathrm{R}^{N^{-1}}+1.4 \mathrm{RLi} \frac{1 \mathrm{ChCl} / 2 \mathrm{Gly}}{\mathrm{rt} \text {, under air, } 3 \mathrm{sec}} \mathrm{R}_{\mathrm{R}}$ (iv)

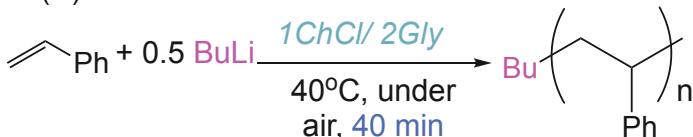


reagents. Harnessing their cooperative effects, these reagents can then be applied to several cornerstone transformations such as deprotonative metallation, metal-halogen exchange or $\mathrm{C}-\mathrm{C}$ bond formation, displaying unique reactivity profiles and exceptional functional group compatibilities, exceeding the limits of traditional single-metal reagents. Adding further sustainability, these enhancements can also be exported to catalytic regimes, through the design of s-block bimetallic catalysts combining built-in Lewis acidic sites with highly nucleophilic 'ate anions.

Towards greener, sustainable, safer chemical transformations, the use of polar organometallic reagents under air and/or with water present has been developed, by pioneering the use of bio-inspired solvents (i.e. DESs, glycerol) as a superior and biorenewable alternative to toxic volatile organic solvents. Although traditionally these reaction conditions have been forbidden in polar organometallic chemistry, our initial studies suggest that this is not an insurmountable challenge. Hints at the untapped potential of these approaches have started to emerge, unlocking a treasure chest of opportunities for the development of sustainable, airand water-compatible s-block metal-mediated organic synthesis. Exploring the reactivity of cooperative bimetallics under air in DESs should open new frontiers in both stoichiometric and catalytic applications of these mixed-metal reagents, creating new opportunities for fine chemicals manufacturing. These additional challenges will not be easily met but the prospect of dispensing with the requirement for dry toxic organic solvents or inert atmospheres will have worldwide implications for the practice of polar organometallic chemistry both in academia and industry.

\section{Acknowledgements}

I am extremely grateful to all the inspiring researchers with whom I have been fortunate enough to work with over the years. First and foremost, my former and current group members, without their talent, enthusiasm and unconditional support, none of this research could have been realised. Thank you for teaching me so many things and for all the fun we have had together! I am also very thankful to my collaborators, Rab Mulvey, Charlie O'Hara (University of Strathclyde, UK), Joaquin García-Álvarez, Alejandro Presa (Universidad de Oviedo, Spain), Vito Capriati (Università di Bari Aldo Moro, Italy) and Vittorio Farina (Janssen Pharmaceutica). I am indebted to the Royal Society, the University of Strathclyde, the UK Engineering and Physical Sciences Research Council (EPSRC), the European Research Council, the University of Bern and the Swiss National Science Foundation for the generous sponsorship of our research. Last but not least, special thanks to Leonie Bole who has helped me with the production of the graphical material included in this article.

Received: July 16, 2020

[1] For a recent historical overview on organolithium chemistry see: $\mathrm{U}$. Wietelmann, J. Klett, Z. Anorg. Allg. Chem. 2018, 644, 194.

[2] C. J. Clarke, W.-C. Tu, O. Levers, A. Bröhl, J. P. Hallett. Chem. Rev. 2018, $118,747$.

[3] A. Harrison-Marchand, F. Mongin, Chem. Rev. 2013, 113, 7470.

[4] F. Mongin, A. Harrison-Marchand, Chem. Rev. 2013, 113, 7563.

[5] D. S. Ziegler, B. Wei, P Knochel, Chem. Eur. J. 2019, 25, 2695.

[6] S. D. Robertson, M. Uzelac, R. E. Mulvey, Chem. Rev. 2019, 119, 8332.

[7] M. Dell'Aera, F. M. Perna, P. Vitale, A. Altomare, A. Palmieri, L. C. H. Maddock, L. J. Bole, A. R. Kennedy, E. Hevia, V. Capriati, Chem. Eur. J. 2020, 26, 8742 .

[8] a) D. Seyferth, Organometallics 2001, 20, 2940; b) J. A. Wanklyn, Liebigs Ann. 1858, 108, 67.

[9] a) M. Uchiyama, T. Furuyama, M. Kobayashi, Y. Matsumoto, K. Tanaka, J. Am. Chem. Soc. 2006, 128, 8404; b) T. Furuyama, M. Yonehara, S. Arimoto, M. Kobayashi, Y. Matsumoto, M. Uchiyama, Chem. Eur. J. 2008, 14, 10348.

[10] Selected references: a) T. Klatt, J. T. Markiewicz, C. Sämann, P. Knochel, J. Org. Chem. 2014, 79, 4253; b) A. Krasovskiy, V. Krasovskaya, P. Knochel, Angew. Chem. Int. Ed. 2006, 45, 2958; c) A. Krasovskiy, P. Knochel, Angew. Chem. Int. Ed. 2004, 43, 3333.

[11] Selected references: a) P. C. Andrikopoulos, D. R. Armstrong, H. R. L. Barley, W. Clegg, S. H. Dale, E. Hevia, G. W. Honeyman, A. R. Kennedy, R. E. Mulvey, J. Am. Chem. Soc. 2005, 127, 6184; b) W. Clegg, S. H.
Dale, E. Hevia, L. M. Hogg, L.M., G. W. Honeyman, R. E. Mulvey, C. T. O'Hara, Angew. Chem. Int. Ed. 2006, 45, 6548; c) A. R. Kennedy, J. Klett, R. E. Mulvey, D. S. Wright, Science 2009, 326, 706; d) A. J. MartínezMartínez, A. R. Kennedy, R. E. Mulvey, C. T. O'Hara, Science 2014, 346, 834.

[12] Some of our work in this area has already be summarised in the following review articles: a) M. Uzelac, R. E. Mulvey, Chem. Eur. J. 2018, 24, 7786;b) M. Uchiyama, C. Wang, Top. Curr. Organomet. Chem. 2014, 47, 159; c) R. E. Mulvey, Acc. Chem. Res. 2009, 42, 743.

[13] For more detailed reviews of our work in the field of air- and moisture-compatible polar organometallic chemistry see: a) J. García-Álvarez, E. Hevia, V. Capriati, Eur. J. Org. Chem. 2015, 6779; b) J. García-Álvarez, E. Hevia, V. Capriati, Chem. Eur. J. 2018, 24, 14854.

[14] W. Clegg, B. Conway, E. Hevia, M. D. McCall, L. Russo, R. E. Mulvey, J. Am. Chem. Soc. 2009, 131, 2375.

[15] D. R. Armstrong, V. L. Blair, W. Clegg, S. H. Dale, J. García-Alvarez, E. Hevia, G. W. Honeyman, R. E. Mulvey, L. Russo, J. Am. Chem. Soc. 2010, $132,9480$.

[16] V. L. Blair, W. Clegg, A. R. Kennedy, Z. Livingstone, L. Russo, E. Hevia, Angew. Chem. Int. Ed. 2011, 50, 9857.

[17] S. E. Baillie, T. Bluemke, W. Clegg, A. R. Kenedy, J. Klett, L. Russo, M. de Tullio, E. Hevia, Chem. Commun. 2014, 50, 12859.

[18] S. E. Baillie, V. L. Blair, D. C. Blakemore, D. Hay, E. Hevia, A. R. Kenendy, D. C. Pryde, Chem. Commun. 2012, 48, 1985.

[19] M. Uzelac, A. R. Kennedy, E. Hevia, R. E. Mulvey, Angew. Chem. Int. Ed. 2016, 55, 13147.

[20] R. McLellan, M. Uzelac, A. R. Kennedy, E. Hevia, R. E. Mulvey, Angew. Chem. Int. Ed. 2017, 56, 9566.

[21] M. Uzelac, A. R. Kennedy, E. Hevia, Inorg. Chem. 2017, 56, 8615.

[22] N. Plé, A.Turck, K. Couture,G.Quéguiner, J. Org.Chem. 1995, 60, 3781

[23] R. McLellan, M. Uzelac, L. J. Bole, J. M. Gil-Negrete, D. R. Armstrong, Alan R. Kennedy, R. E. Mulvey, E. Hevia, Synthesis, 2019, 51, 1207.

[24] D. R. Armstrong, S. E. Baillie, V. L. Blair, N. G. Chabloz, J. Diez, J. GarciaAlvarez, A. R. Kennedy, S. D. Robertson, E. Hevia, Chem. Sci. 2013, 4, 4259.

[25] M. Uzelac, E. Hevia, Chem. Commun. 2018, 54, 2455.

[26] A. Hernán-Gómez, M. Uzelac, S. E. Baillie, D. R. Armstrong, A. R. Kennedy, M. A. Fuentes, E. Hevia, Chem. Eur. J. 2018, 24, 10541.

[27] A. Martínez-Martínez, M. A. Fuentes, A. Hernán-Gómez, E. Hevia, A. R. Kennedy, R. E. Mulvey, C. T. O'Hara, Angew. Chem. Int. Ed. 2015, 54, 14075.

[28] A. Hernán-Gómez, A. R. Kennedy, E. Hevia, Angew. Chem. Int. Ed, 2017, $56,6632$.

[29] L. C. H. Maddock, T. Cadenbach, A. R. Kennedy, I. Borilovic, G. Aromí, E. Hevia, Inorg. Chem. 2015, 54, 9201.

[30] M. Uzelac, I. Borilovic, M. Amores, T. Cadenbach, A. R. Kennedy, G. Aromí, E. Hevia, Chem. Eur. J. 2016, 22, 4843

[31] L. C. H. Maddock, I. Borliovic, J. McIntyre, A. R. Kennedy, G. Aromí, E. Hevia, Dalton Trans. 2017, 46, 6683

[32] L. C. H. Maddock, T. Nixon, A. R. Kennedy, M. R. Probert, W. Clegg, E. Hevia, Angew. Chem. Int. Ed. 2018, 57, 187.

[33] a) J. Z. Chua, P. García-Álvarez, E. Hevia, A. R. Kennedy, M. D. McCall, Proc. Natl. Acad. Sci. USA, 2010, 107, 5294; b) T. D. Bluemke, W. Clegg, P. Garcia-Alvarez, K. Koszinowski, M. D. Call, L. Russo, E. Hevia, Chem. Sci. 2014, 5,3552

[34] a) D. Tilly, F. Chevallier, F. Mongin, P. C. Gros, Chem. Rev. 2014, 114, 1207; b) T. Furuyama, M. Yonehara, S. Arimoto, M. Kobayashi, Y. Matsumoto, M. Uchiyama, Chem. Eur. J. 2008, 14, 10348.

[35] M. Balkenhohl, D. S. Ziegler, A. Desaintjean, L. J. Bole, A. R. Kennedy, E. Hevia P. Knochel, Angew. Chem. Int. Ed. 2019, 58, 12898.

[36] A. Hernán-Gómez, E. Herd, M. Uzelac, T. Cadenbach, A. R. Kennedy, I. Borilovic, G. Aromí, E. Hevia, Organometallics 2015, 34, 2614.

[37] Selected examples: a) R. Li, Z. Wen, N. Wu, Org. Biomol. Chem. 2016, 14, 11080; b) R. Lerebours, C. Wolf, Org. Lett. 2007, 9, 2737; c) Z.-Q. Wang, C.-G. Feng, S.-S. Zhang, M.-H. Xu, G.-Q. Lin, Angew. Chem. Int. Ed. 2010, 49, 5780. d) K.-C. Huang, B. Gopula, T.-S. Kuo, C.-W. Chiang, P.-Y. Wu, J. P. Henschke, Org. Lett. 2013, 15, 5730.

[38] A. Hernán-Gómez, S. A. Orr, M. Uzelac, A. R. Kennedy, S. Barroso, X. Jusseau, S. Lemaine, V. Farina, E. Hevia, Angew. Chem. Int. Ed. 2018, 57, 10630.

[39] a) M. S. Hill, D. J. Liptrot, C. Weetman, Chem. Soc. Rev. 2016, 45, 972; b) A. G. M. Barrett, M. R. Crimmin, M. S. Hill, P. A. Procopiou, Proc. R. Soc. A 2010, 466, 927.

[40] B. Liu, T. Roisnel, J. F. Carpentier, Y. Sarazin, Angew. Chem. Int. Ed. 2012 $51,4943$.

[41] a) A. Hernán-Gómez, T. D. Bradley, A. R. Kennedy, Z. Livingstone, S. D. Robertson, E. Hevia, Chem. Commun. 2013, 49, 8659; b) M. De Tullio, A. Hernán-Gómez, Z. Livingstone, W. Clegg, A. R. Kennedy, R. W. Harrington, A. Antiñolo, A. Martínez, F. Carrillo-Hermosilla, E. Hevia, Chem. Eur. J. 2016, $22,17646$.

[42] L. Davin, A. Hernán-Gómez, C. McLaughlin A. R. Kennedy, R. McLellan, E. Hevia, Dalton Trans, 2019, 48, 8122. 
[43] M. Fairley, L. Davin, A. Hernan-Gomez, J. Garcia-Alvarez, C. T. O’Hara, E. Hevia, Chem. Sci. 2019, 10, 5821.

[44] C. Vidal, J. Garcia-Alvarez, A. Hernan-Gomez, A. R. Kennedy, E. Hevia, Angew. Chem. Int. Ed. 2014, 53, 5969.

[45] C. Vidal, J. García-Álvarez, A. Hernán-Gómez, A. R. Kennedy, E. Hevia, Angew. Chem. Int. Ed. 2016, 55, 16145.

[46] M. J. Rodriguez-Alvarez, J. Garcia-Alvarez, M. Uzelac, M. Fairley, C. T. O'Hara, E. Hevia, Chem. Eur. J. 2018, 24, 1720.

[47] Q. Zhang, K. De Oliveira Vigier, S. Royer, F. Jérôme, Chem. Soc. Rev. 2012, 41, 7108 .

[48] a) M. Francisco, A. van den Bruinhorst, M. C. Kroon, Angew. Chem. Int. Ed. 2013, 52, 307; b) E. L. Smith, A. P. Abbott, K. S. Ryder, Chem. Rev. 2014 114, 11060; c) A. Paiva, R. Craveiro, I. Aroso, M. Martins, R. L. Reis, A. R. C. Duarte, ACS Sus. Chem. Eng. 2014, 2, 1063.

[49] A. Sánchez-Condado, G. A. Carriedo, A. Presa Soto, M. J. RodríguezÁlvarez, J. García-Álvarez, E. Hevia, ChemSusChem 2019, 13, 3134.

[50] M. Fairley, L. J. Bole, F. F. Mulks, L. Main, A. R. Kennedy, C. T. O’Hara, J. Garcia-Alvarez, E. Hevia, Chem. Sci. 2020, 11, 6500.

\section{License and Terms}

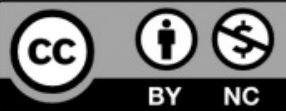

This is an Open Access article under the terms of the Creative Commons Attribution License CC BY_NC 4.0. The material may not be used for commercial purposes. The license is subject to the CHIMIA terms and conditions: (http:// chimia. .ch/component/sppagebuilder/?view = page $\& i d=12$ ).

The definitive version of this article is the electronic one that can be found at https://doi.org/10.2533/chimia.2020.681 